\title{
Mycobacterial Growth
}

\author{
Iria Uhía ${ }^{1}$, Kerstin J. Williams ${ }^{1}$, Vahid Shahrezaei ${ }^{2}$, and Brian D. Robertson ${ }^{1}$ \\ ${ }^{1}$ Department of Medicine, MRC Centre for Molecular Bacteriology and Infection, Imperial College London, \\ London, SW7 2AZ, United Kingdom \\ ${ }^{2}$ Department of Mathematics, Imperial College London, London, SW7 2AZ, United Kingdom \\ Correspondence: b.robertson@imperial.ac.uk
}

\begin{abstract}
In this work, we review progress made in understanding the molecular underpinnings of growth and division in mycobacteria, concentrating on work published since the last comprehensive review (Hett and Rubin 2008). We have focused on exciting work making use of new time-lapse imaging technologies coupled with reporter-gene fusions and antimicrobial treatment to generate insights into how mycobacteria grow and divide in a heterogeneous manner. We try to reconcile the different observations reported, providing a model of how they might fit together. We also review the topic of mycobacterial spores, which has generated considerable discussion during the last few years. Resuscitation promoting factors, and regulation of growth and division, have also been actively researched, and we summarize progress in these areas.
\end{abstract}

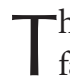
he answers to many biological questions are facilitated by technological advances that allow us to observe and interrogate objects easier, faster, and more accurately than before. Time-lapse observations of bacteria have been around for many years, even for more difficult to grow prokaryotes, such as mycobacteria. Elegant studies by Brieger and Glauert more than 60 yr ago show what can be performed with ingenuity and patience (Brieger and Glauert 1952, 1956; Brieger et al. 1953, and references therein). We now have autofocus microscopes with motorized stages, digital cameras with more and more pixels, and software to control it all. Historically, the basics of growing bacteria for imaging used bacterial agar; recently, however, microfluidics arrived on the microscope stage, which allowed us to grow bacteria in suspension and to control growth conditions with relative ease. These systems make it possible to change growth medium in a controlled manner, introduce antimicrobials, and image what happens, as frequently as the bacteria will tolerate exposure to the high-intensity light needed to excite the fluorophores they express. The availability of commercial systems means that investigations of bacterial growth and division and the response to environmental changes are once again only constrained by our ingenuity.

\section{MYCOBACTERIAL IMAGING}

Technological advances in micro- and nanotechnology permit the study of microorganisms at the single-cell level. Electron microscopy provided insights into mycobacterial cell division (Dahl 2004), showing Mycobacterium tuberculosis forming branching structures with

Editors: Stefan H.E. Kaufmann, Eric J. Rubin, and Alimuddin Zumla

Additional Perspectives on Tuberculosis available at www.perspectivesinmedicine.org

Copyright (C) 2015 Cold Spring Harbor Laboratory Press; all rights reserved; doi: 10.1101/cshperspect.a021097

Cite this article as Cold Spring Harb Perspect Med 2015;5:a021097 
I. Uhía et al.

V-shaped cells undergoing a "snapping” mechanism of cell division common to actinomycetes. Electron micrographs allow high cellular detail to be visualized, but tell nothing about the dynamics of cell division and chromosome segregation; this requires time-resolved images that represent separate growth stages to visualize the process in its entirety. Live-cell time-lapse imaging allows single cells to be imaged periodically, so that the movement of a protein during cell growth and division can be observed directly and quantified to assess cell-to-cell variability (Locke and Elowitz 2009). Advances in microscopy, fluorescent proteins, and dye technologies have allowed multiple protein and cellular structures to be viewed simultaneously, which, coupled with time-lapse imaging, is emerging as a powerful tool to investigate mycobacterial cell division.

\section{Live-Cell Time-Lapse Imaging}

To date, only a few studies of cell division in mycobacteria have been reported using this technology (Joyce et al. 2011, 2012; Aldridge et al. 2012; Golchin et al. 2012; Santi et al. 2013; Wakamoto et al. 2013). The method is not without challenges; mycobacteria grow slowly and tend to divide to form disorganized microcolonies, which impacts on the imaging protocol to ensure the microscopy conditions remain permissive for growth and capture in-focus images. Fluorescence microscopy requires an excitation source (laser, xenon, or helium lamp) to produce a detectable emission from the fluorophore, but prolonged high-intensity light causes phototoxicity, affecting cell viability. Two methods of growing mycobacteria on thin agar pads or in microfluidic devices, both housed in temperature controlled chambers and imaged by bright-field or confocal microscopy, have been reported. Growth on thin agar pads on a microscope slide has been used to study fundamental processes such as bacterial growth patterns, protein localization dynamics, antibiotic action, and bacterial persistence (Fiebig et al. 2006; Thanbichler and Shapiro 2006; Letek et al. 2008). However, the environmental conditions are difficult to manipulate, and it is challenging to prevent desiccation of the agar pad and maintain levels of oxygen and nutrients for the longer experiments needed for slowgrowing mycobacteria. A modified agar pad method for mycobacteria was developed (Joyce et al. 2011) using glass-bottomed dishes and an agar pad, with the bacteria sandwiched between coverslip and agar, and imaged with an inverted microscope. This method allowed imaging over longer times ( $>65 \mathrm{~h}$ ); can be used with fluorescence microscopy and permits some manipulation of environmental conditions, by diffusion through the thin agar pad during imaging (Joyce et al. 2012). The availability of multiwell glassbottomed plates and automated microscope stages means that this method could be used for higher-throughput analyses. However, more complex alterations of environmental conditions, such as changing the medium composition or removal of antibiotics, are impractical.

Microfluidic devices are more sophisticated and expensive, but they are a rapidly advancing technology, with commercial platforms now available as an alternative to in-house devices. This technology has been used to study mycobacterial cell division (Aldridge et al. 2012; Golchin et al. 2012; Santi et al. 2013; Wakamoto et al. 2013). Typical custom-built microfluidic devices use photolithographic methods to create a positive template of microchannels which is used to cast negative-aspect replicas in polydimethylsiloxane (PDMS). The PDMS structures are bonded to glass slides, and holes are added to make input and output channels for the addition and removal of growth medium using syringe pumps (Aldridge et al. 2012; Golchin et al. 2012; Santi et al. 2013; Wakamoto et al. 2013). Continuous perfusion of the cells ensures a suitable growth environment for longterm experiments and permits manipulation of environmental conditions, such as the addition or removal of antibiotics. Such devices have the advantage that they can restrict movement of the cells in the Z-plane, keeping them in focus, although it is unclear as yet whether this is detrimental to mycobacterial growth. To date, only imaging of the fast-growing Mycobacterium smegmatis has been reported using microfluidics. Recent advances include the development 
of microfluidic plates and automated perfusion systems (e.g., the CellASIC ONIX Microfluidic Perfusion Platform [Lee et al. 2009]) permitting higher-throughput and automated methods of single-cell tracking. Although not without drawbacks, live-cell imaging using microfluidics is arguably now the method of choice, and it will be interesting to see if super-resolution microscopy can be incorporated into such systems.

\section{ASYMMETRIC GROWTH}

Several groups have studied cell elongation and septum placement in mycobacteria, reaching different conclusions about the asymmetry or symmetry of these processes. However, some of the disagreements may be attributed to the use of different experimental conditions and analysis methods (Table 1 and Fig. 1), as will be discussed below.

\section{Unipolar/Bipolar Growth}

The absence from actinomycete genomes of the actin homolog MreB, which directs lateral wall biogenesis (Carballido-López 2006), together with the localization of nascent peptidoglycan synthesis to the cell tips of mycobacterial and corynebacterial cells, supports polar growth in these bacteria (Daniel and Errington, 2003; Thanky et al. 2007; Hett and Rubin 2008). Additional work showed a role for Wag31-homo$\log$ of the Gram-positive cell-division protein DivIVA - in the maintenance of cell morphology (Kang et al. 2008).

Polar growth has been the topic of several recent studies. Aldridge et al. (2012) proposed that mycobacterial growth is unipolar and mainly from the old cell pole. However, exclusively unipolar growth was not observed by other authors, although some did notice a different growth rate between poles without reference to pole age (Joyce et al. 2012; Singh et al. 2013). Another study showed the same rate of mycobacterial growth from both poles (Santi et al. 2013). According to the Aldridge model, after division, one daughter cell inherits the growing (old) pole, whereas its sibling creates a new growth pole, leading to a slower elongation rate. As the growth pole matures, cells elongate faster and birth length increases, assuming that cell cycle is dependent on time, not cell size (Aldridge et al. 2012). The results and conclusions reached by Santi et al. (2013) are nonetheless quite different. In their model, old and new poles elongate at the same rate. However, they quantified exponential growth rate, considering elongation velocity to be size-dependent (larger cells growing faster), and their data show that the cells inheriting the old pole tend to be larger at division and so grow faster than the new pole cells (Santi et al. 2013). The elongation rate remains nevertheless the same in sibling cells, as described by Wakamoto et al. (2013). Thus, this model supports the exponential growth of single cells, as suggested for other bacteria (Godin et al. 2010; Mir et al. 2011), and is in agreement with a size-control mechanism that would prevent cells from dividing before reaching a minimum size; once achieved, the division would proceed in a random fashion (Santi et al. 2013).

\section{Antibiotic Susceptibility/Persistence}

Supporters of unipolar growth suggested related consequences for antibiotic susceptibility (Aldridge et al. 2012). The cells inheriting the growing pole were more sensitive to several peptidoglycan synthesis inhibitors, as expected, and also to isoniazid, targeting mycolic acid synthesis, but more resistant to the RNA polymerase inhibitor, rifampicin (Aldridge et al. 2012). Thus, variability in the susceptibility of these two populations of cells to antibiotics was proposed (Aldridge et al. 2012). The association between growth rates and sensitivity to isoniazid was later challenged, as other investigators did not find a correlation (Wakamoto et al. 2013). In contrast, a weak positive association was described between survival in the presence of isoniazid and the inheritance of the old pole (Wakamoto et al. 2013). Santi et al. (2013) also did not find any difference between old pole and new pole cells regarding sensitivity to the antibiotics tested by Aldridge et al. (2012), although the possibility that the different techniques used 
I. Uhía et al.

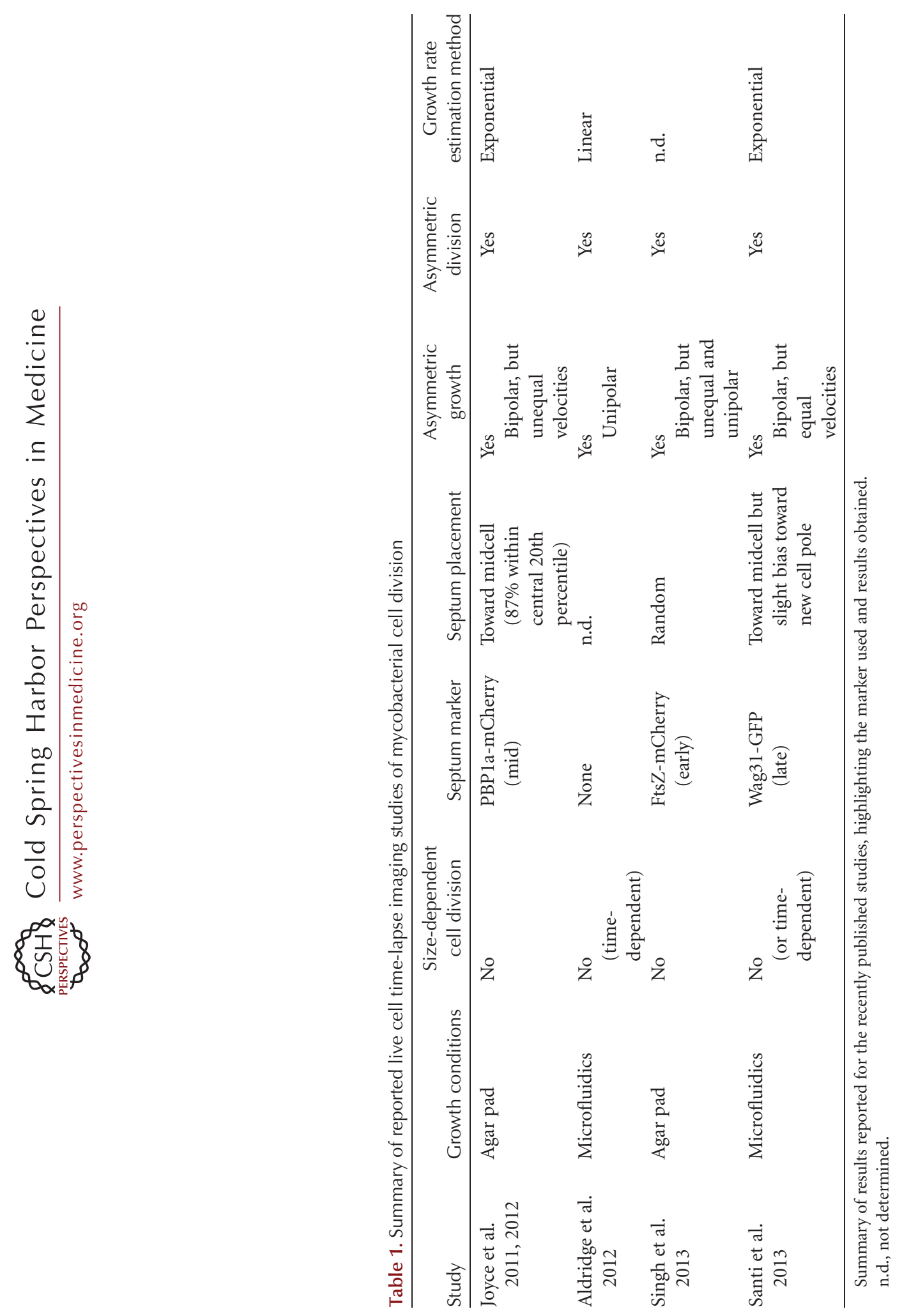




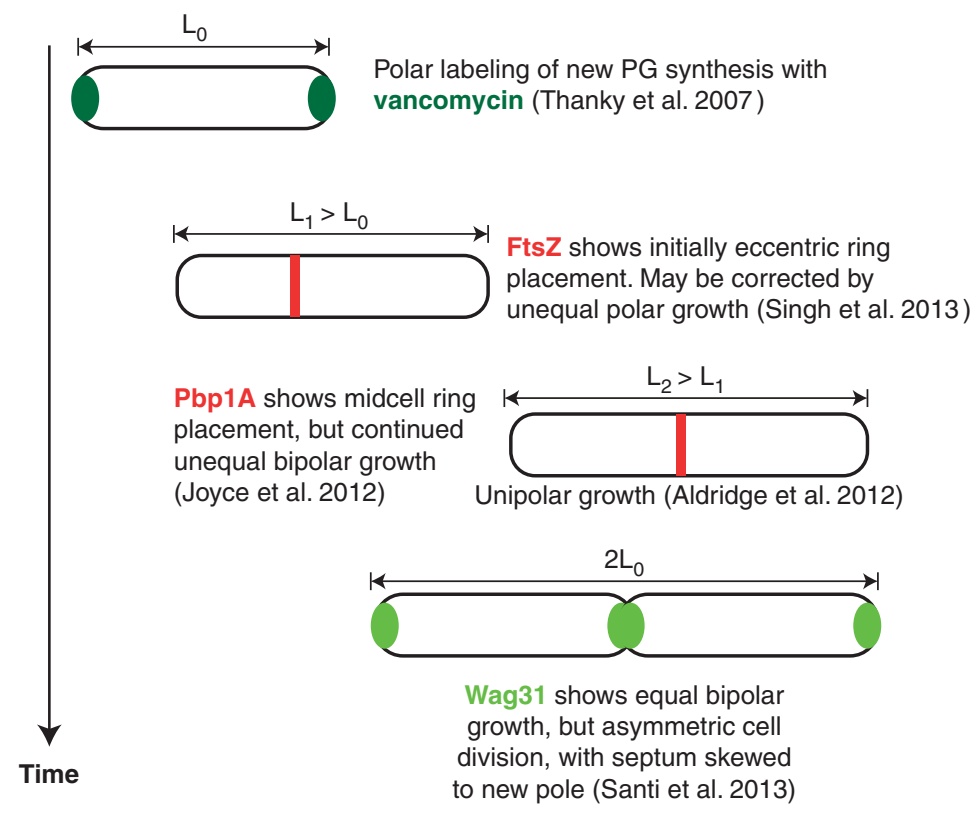

Figure 1. Cartoon summarizing the results published to date on mycobacterial cell division using time-lapse imaging. A timeline has been constructed to try to reconcile the different results reported for polar and asymmetric growth. PG, peptidoglycan.

could affect the results cannot be discarded (Santi et al. 2013). Survival in the presence of isoniazid was attributed to single-cell dynamics of KatG, the isoniazid-activating enzyme; cells expressing KatG in stochastic pulses would be more sensitive to the drug (Wakamoto et al. 2013). As the survival of sibling cells was positively correlated, it was suggested that epigenetics contribute to this phenomenon. This result supports the opinion that persistent cells may continue to grow in the presence of antibiotics and that the stochastic expression of any factor which promotes or inhibits the activity of the antibiotic could be key in the survival of single cells (Wakamoto et al. 2013). That the persistent state of M. tuberculosis in chronic infection may be attributable to on-going bacterial replication is in opposition to models that defend a nonreplicating state (Gill et al. 2009). Other work on M. smegmatis showed that some cells exit dormancy stochastically and independently of time or environmental factors, perhaps through the stochastic expression or repression of a master regulatory gene (Buerger et al. 2012). These results suggest that slowing of growth may not be the only common strategy for microorganisms to achieve persistence (Buerger et al. 2012).

\section{Septum Positioning}

The apparently asymmetric septum placement observed could be a consequence of the asymmetric polar growth reported (Aldridge et al. 2012; Joyce et al. 2012; Singh et al. 2013). Indeed, this is the conclusion of Joyce et al. (2012), using penicillin-binding protein 1a (PBP1a) and Van-BODIPY as markers of poles and septum, respectively. They found that septum placement is less accurate in mycobacteria than in corynebacteria, but a mid-cell position was favored. However, this was altered by subsequent unequal polar growth, leading to asymmetric division. Septum placement was independent of cell length (Joyce et al. 2012); other investigators state that cells need to reach a critical size before division (Santi et al. 2013; Singh et al. 2013). Singh et al. (2013) showed that FtsZ ring positioning was nearly random, but when using membrane (FM4-64) or cell wall (FLVanco) markers, the septum position was found 
I. Uhía et al.

to be more symmetric. Finally, when using the late-division protein Wag31 as a septum marker, it was biased toward the new pole (Santi et al. 2013). These discrepancies might be because of the use of different markers; FtsZ is probably the earliest component in septum formation, with membranes, PBP1a, and cell wall components recruited at later stages. Alternative explanations taking this into account may bring these apparently disparate observations together. If the FtsZ ring is placed nonsymmetrically, then subsequent unequal polar growth may lead to an apparent mid-cell positioning of later septum components. As growth continues, the septum is again found in an asymmetric position before cell division, when Wag31 is located there (Joyce et al. 2012; Santi et al. 2013; Singh et al. 2013). Asymmetric division sites have been reported over the nucleoids, requiring a DNA translocase to transfer the DNA through the septum before it closes (Singh et al. 2013); however, this has not been reported by others. More observations are required to account for the heterogeneity reported in mycobacterial growth and division, and investigations using consensus cell division markers in the different experimental systems would further help clarify the situation.

Asymmetric growth and division is widespread in bacteria and may have evolved multiple times (Kysela et al. 2013), because it influences population aging and produces phenotypic heterogeneity. This could provide fitness advantages for the population through a bet-hedging strategy (Kussell and Leibler 2005). The recent work in mycobacteria suggests that phenotypic heterogeneity could arise at multiple levels through asymmetric polar growth and inaccurate cell division. The ultimate importance of the specific forms of growth asymmetries in host-pathogen interactions is a key area for further investigations.

\section{Drug-Resistant Strains: Growth and Division}

It is interesting to note the characteristic morphology observed in resistant M. tuberculosis strains (Velayati et al. 2009a,b; Farnia et al. 2010). During exponential growth, multidrugresistant (MDR) and susceptible isolates are mainly rod-shaped, whereas oval, rounded, or branching cells are seen in extensively drugresistant (XDR) isolates (Farnia et al. 2010). XDR subpopulations also displayed an extremely thick wall (Velayati et al. 2009b). Symmetrical, asymmetrical, and branching division were observed in all isolates, but XDR isolates displayed a novel division type in which a rodshaped mother cell produced a small round bacillus (Farnia et al. 2010). These changes in morphology may help these strains escape immune responses and adapt to the host environment (Champion and Mitragotri 2006; Farnia et al. 2010).

\section{CHROMOSOME SEGREGATION}

Before cell division, the replicated chromosomes must be partitioned into the daughter cells. The presence of chromosomal homologs of the genes needed to segregate low-copynumber plasmids during cell division raises the possibility that chromosomes are segregated in a similar way. Both plasmid and chromosome encoded par loci consist of an ATPase (ParA), a site-specific DNA-binding protein (ParB) that interacts with ParA, and a DNA sequence motif ( $p a r S$ ) to which ParB binds. The type I plasmidencoded par loci encode a Walker A Cytoskeletal ATPase and are the ones also found on bacterial chromosomes (Ebersbach and Gerdes 2005).

The chromosomal ParAB system has been studied in several bacteria including Mycobacterium spp. (Jakimowicz et al. 2007; Casart et al. 2008; Maloney et al. 2009; Nisa et al. 2010; Chaudhuri and Dean 2011; Ginda et al. 2013). In Caulobacter crescentus (Ptacin and Shapiro 2010), the only species in which parA and parB are essential, a model was proposed in which ParA dimerizes when bound to ATP and forms linear polymers. These polymers are dissociated from the ends, stimulated by the binding of the ParB-parS partition complex. As ParA depolymerizes, the partition complex moves toward the new pole during chromosome segregation.

Chromosomal par loci are located proximal to and upstream of oriC (Lin and Grossman 1998). Genes homologous to parA and parB have been identified in all mycobacteria se- 
quenced so far (Jakimowicz et al. 2007). Two parS copies, identical to those in Streptomyces coelicolor (Jakimowicz et al. 2002), have been identified in M. smegmatis, Mycobacterium bovis BCG (Bacillus Calmette-Guérin) and M. tuberculosis (Jakimowicz et al. 2007; Casart et al. 2008), and a third parS copy with one mismatch to the consensus is also located close to oriC. These parS sequences interact with ParB in M. smegmatis (Jakimowicz et al. 2007). The par genes are arranged in an operon, where they cluster with another six conserved genes (including gidB), upstream and divergent to the $d_{n a A}$ gene (Casart et al. 2008). One parS sequence is located in the gidB promoter, and the other is in the coding region of parA, suggesting that $\operatorname{par} B$ could regulate both $\operatorname{gid} B$ and parA expression and control the levels of Par proteins (Casart et al. 2008). Indeed, the amino-terminal domain of ParB does interact with parS (Chaudhuri and Dean 2011). The mycobacterial ParB-parS partition complex involves ParB-ParB interactions (Ginda et al. 2013). On binding to parS sequences, it has been proposed that in $M$. tuberculosis, ParB dimers undergo a drastic compaction, which primes ParB spreading on the parS-adjacent DNA scaffold to form the type of higher-order partition assembly (Chaudhuri and Dean 2011) described for other bacteria (Murray et al. 2006; Breier and Grossman 2007).

The parA and parB genes are annotated as essential in M. tuberculosis based on transposon mutagenesis (Sassetti et al. 2003; Zhang et al. 2012). However, they are nonessential in M. smegmatis (Jakimowicz et al. 2007; Ginda et al. 2013), in which both locate to the poles of the cell (Maloney et al. 2009; Ginda et al. 2013). However, this localization pattern was only studied with static microscopy, and it may be dynamic in live cells, as seen in C. crescentus (Ptacin and Shapiro 2010). In fact, a gradient of ParA from one pole toward the other has been observed in $M$. smegmatis using in vivo timelapse microscopy (G Joyce, KJ Williams, and BD Robertson, unpubl.). In contrast in Corynebacterium glutamicum, ParB remains stably attached to the cell poles during time-lapse experiments (Donovan et al. 2010). The bipolar localization of ParB observed in static microscopy is altered when parA is deleted; however, the deletion of parB does not seem to alter ParA localization, suggesting that mislocalized partition complexes have a more negative influence on chromosome segregation than their complete absence (Ginda et al. 2013).

Overproduction or deletion of ParA or ParB causes growth inhibition and severe chromosome segregation defects (Jakimowicz et al. 2007; Maloney et al. 2009; Ginda et al. 2013). Deletion of either parA or parB leads to a high percentage of anuclear cells, three times higher in the parA deletion strain (Ginda et al. 2013). Surprisingly, the par $A B$ mutants have milder growth defects and fewer anucleate cells, suggesting that a specific ParA:ParB ratio is crucial for correct operation. ParA colocalizes and interacts with Wag31, and aberrations in cell length (elongated or shortened cells) were observed in all three mutants (Ginda et al. 2013). Thus, the ParAB system could coordinate chromosome segregation with other cell cycle processes through interaction with a polar determinant, as has been proposed in C. crescentus and C. glutamicum (Ptacin and Shapiro 2010; Donovan et al. 2012).

To achieve a mechanistic understanding of chromosome segregation, septum placement, asymmetric growth, and their interdependence, mathematical modeling of the spatiotemporal dynamics of the key players will be essential. Similar modeling approaches have provided insight into the Min system in Escherichia coli (Kruse et al.2007) and ParAB-mediated plasmid partitioning (Ringgaard et al. 2009). Quantitative data can be used to test the validity of different mechanisms, for example, theory sets physical limits to the positional information and accuracy provided by protein gradients (Tostevin et al. 2007). Modeling can also shed light on fitness advantages of observed asymmetries and heterogeneities in growth and division (Kussell and Leibler 2005).

\section{Regulation of Growth and Cell Division}

Bacterial eukaryotic-type serine/threonine protein kinases (STPKs) transmit signals from the 
I. Uhía et al.

extracellular environment via the reversible phosphorylation of proteins, permitting bacteria to adapt to external changes. In mycobacteria, these kinases are thought to be involved in several processes, including cell shape, growth, and cell division. M. tuberculosis possesses 11 STPKs (PknA-PknL, except C), whose biochemical activity and substrates have been widely studied and reviewed (Hett and Rubin 2008; Molle and Kremer 2010). More recently, PknA and $\mathrm{PknB}$ have been implicated in the phosphorylation of the lone Ser/Thr phosphatase (PstP) in M. tuberculosis, suggesting a signaling regulation of STPKs/PstP through mutually dependent mechanisms (Sajid et al. 2011). PknB — which localizes at mid-cell and poles (Mir et al. 2011)—phosphorylates the peptidoglycan biosynthetic protein MviNP, leading to the recruitment of FhaA, which modulates peptidoglycan synthesis at the cell poles and septum (Gee et al. 2012; Warner and Mizrahi 2012). Osmotic stress stimulates a signaling pathway in M. tuberculosis regulated by $\mathrm{PknD}$ (Hatzios et al. 2013). PknE kinase has been implicated in the suppression of apoptosis during nitrate stress and an adaptive response regulating cellular integrity and survival (Kumar and Narayanan 2012; Kumar et al. 2013). PknI and PknK are thought to be involved in slowing the growth of $M$. tuberculosis during infection (Gopalaswamy et al. 2009; Malhotra et al. 2010), whereas PknJ phosphorylation of pyruvate kinase A (mtPykA) affects central metabolism (Arora et al. 2012) and PknL may modulate apoptosis (Lakshminarayan et al. 2008).

Two-component systems (TCSs) are formed by a sensor kinase that autophosphorylates when receiving signals from the environment, transferring a phosphoryl group to a response regulator, which then activates specific regulons for adaptation to the signal sensed. M. tuberculosis encodes 11 TCSs, and the MtrAB system has been implicated in the maintenance of cell wall integrity (Moker et al. 2004; Cangelosi et al. 2006; Nguyen et al. 2010; Plocinska et al. 2012). Expression of the MtrA regulon is necessary for regulated cell division, and one of these genes encodes the essential cell wall hydrolase RipA (Plocinska et al. 2012). MtrB localizes at the cell poles, membranes, and septa in an FtsZdependent manner, and MtrA regulon expression is compromised under conditions that interfere with MtrB septal localization, suggesting that MtrB sensor kinase activation takes place at the septum (Plocinska et al. 2012).

\section{Rpfs}

The first resuscitation promoting factor protein (Rpf) was described in Micrococcus luteus (Mukamolova et al. 2002). Its name indicates its capacity to promote the resuscitation of dormant bacteria. This secreted protein has homologs among other high G + C Gram-positive bacteria, including Mycobacterium spp. M. tuberculosis contains five Rpf homologs, RpfA-E, scattered throughout the genome, that can resuscitate dormant BCG or M. tuberculosis (for review, see Kana and Mizrahi 2010). All of them contain putative signal sequences at the amino terminus, suggesting that they are active extracellularly (Kana and Mizrahi 2010). Rpfs share a conserved 70-amino-acid region, the Rpf domain, responsible for biological activity (Mukamolova et al. 2002). This domain is similar to C-type lysozyme and the E. colisoluble lytic transglycosylase 70 (Cohen-Gonsaud et al. 2005), both involved in the degradation of peptidoglycan; the muralytic activity of this family of proteins has been shown (Mukamolova et al. 2006; Telkov et al. 2006). Peptidoglycan hydrolysis could produce muropeptides that might modulate innate immune responses or activate the cell resuscitation pathway (Jo 2008; Kana and Mizrahi 2010; Nikitushkin et al. 2013). Recently, a novel class of 2-nitrophenylthiocyanates has been found to inhibit the muralytic activity of Rpfs and prevent the resuscitation of dormant M. smegmatis and M. tuberculosis, which makes them interesting candidate compounds against nonreplicating mycobacteria (Demina et al. 2009). The crystal structure of RpfB catalytic domain in complex with the lysozyme inhibitor NAG3 suggests that Glu-292 is the sole residue essential for catalysis in this protein (Squeglia et al. 2013). The use of the structure of RpfB to model the catalytic domains of the other four Rpfs 
Mycobacterial Growth

shows a high degree of similarity but also differences among these five proteins (Squeglia et al. 2013). The expression of all five $r p f s$ varies in the function of the growth phase and under different stress conditions, but all of them are expressed in the early exponential phase, and the relative expression of all five is enhanced in resuscitation phase (Gupta et al. 2010). Differential expression of the five $r p f$ genes in M. tuberculosis appears to be related to differential regulation. $r p f A$ has been shown to be regulated by the cAMP receptor protein, and $r p f C$ by the alternative $\sigma$ factor SigD and the site two protease homolog, Rv2869c (Raman et al. 2004; Makinoshima and Glickman 2005; Rickman et al. 2005).

The five $M$. tuberculosis rpf genes are not essential for growth in vitro and in vivo, individually or collectively (Downing et al. 2004; Tufariello et al. 2004; Kana et al. 2008), but triple, quadruple, and quintuple mutants show impaired spontaneous resuscitation in vitro and are attenuated in vivo (Downing et al. 2005; Kana et al. 2008). The quintuple mutants show increased sensitivity to inhibitors of late peptidoglycan biosynthesis steps, probably owing to increased cell envelope permeability (Kana et al. 2010; Wivagg and Hung 2012). The in vivo attenuation of the multiple mutants led to their consideration as novel vaccine candidates. Both quadruple $r p f$ deletion mutants, $\triangle \mathrm{ACBD}$ and $\triangle \mathrm{ACDE}$, induced protection in the mouse model of tuberculosis infection (Kondratieva et al. 2011). RpfB and RpfE are sufficient for normal growth, suggesting a functional hierarchy (Kana et al. 2008), and both interact with the cell wall hydrolase RipA, whereas RpfB and RipA colocalize in the septum of dividing cells, suggesting that the RpfB-RipA interactions could be involved in the separation of daughter cells during reactivation (Hett et al. 2007, 2008). RipA also interacts with the PBP1, a peptidoglycan-synthesizing enzyme, and a model was proposed in which PBP1 competes with RpfB for binding to RipA, thus limiting RipA-RpfB peptidoglycan hydrolyzing activity (Hett et al. 2010). RpfB is considered a promising candidate for inclusion in novel tuberculosis vaccines (Romano et al. 2012).

\section{THE CONTROVERSY OF MYCOBACTERIAL SPORULATION}

The ability of $M$. tuberculosis to cause long-term subclinical infections that later develop into clinically active disease is one of the main obstacles to tuberculosis control. The production of spores by mycobacteria could be a bacterial strategy to survive during this long subclinical phase, but this possibility has not been widely accepted. Studies from the 1950s suggested the existence of spores in old mycobacterial cultures (e.g., see Brieger and Glauert 1956), but they were not reproducible and often declared to be caused by contamination or artifacts (for references, see Traag et al. 2010 and Singh et al. 2010).

More recently, Ghosh et al. (2009) reported the existence of endospores in old cultures of M. marinum on solid agar medium and suggested their existence in M. bovis BCG. To ensure the absence of contaminants, the germination of individual endospores was tracked, as was the return to sporulation in late stationary phase. An endospore-like structure was visualized using transmission electron microscopy, and the M. marinum endospores tested positive for spore-specific stains, resistance to heat and chemical stress, and the presence of dipicolinic acid (Ghosh et al. 2009). These investigators also suggested that the asymmetric placement of the septum during cell division observed in mycobacteria could be in agreement with their ability to form spores (Singh et al. 2010).

These results (Ghosh et al. 2009) were disputed by Traag et al. (2010), who failed to detect the presence of spores in $M$. marinum cultures after reproducing the experimental procedures of Gosh and colleagues. They were also unable to recover spores from frogs chronically infected by $M$. marinum. The observation that the endospores found were strikingly similar to those of Bacillus subtilis (Ghosh et al. 2009) suggested a possible contamination of the samples. In a follow-up paper from the Kirsebom laboratory, differences in the appearance between these two kinds of spores were reported (Singh et al. 2010). Traag et al. (2010) showed that mycobacteria lack orthologs of key genes involved in 
I. Uhía et al.

endospore formation in low G + C Gram-positive bacteria, perhaps unsurprising for high $\mathrm{G}$ $+\mathrm{C}$ mycobacterium species. It has also been noted that although rare, some species of Streptomyces can form endospores under specific conditions (Stastná et al. 1992) and that the absence of homologous sporulation genes does not prove the absence of proteins with similar function (Singh et al. 2010).

Although it remains possible that spores might be produced by $M$. marinum under certain conditions, Traag et al. (2010) were unable to reproduce this. More recently, spore-like structures were reported in a 1-yr-old liquid culture of Mycobacterium avium subsp. paratuberculosis (MAP) (Lamont et al. 2012). These spores were resistant to heat and chemical stresses and positive for MAP 16sRNA and dipicolinate, but not for gene elements of wellknown endospore-forming strains. Although these resemble endospores, the authors note that they are also reminiscent of Streptomyces spp. aerial hyphae spores. The fact that MAP has been found as a contaminant in pasteurized food supports the existence of spores in this species (Lamont et al. 2012). The existence of spores in mycobacterium species is still controversial, and the exact conditions leading to their formation need to be more widely studied to produce sufficient data to clarify the situation.

\section{CONCLUSIONS}

This is an exciting time for research on bacteria at the single-cell level, and we now have the tools to address questions about phenotypic variation within genetically clonal populations, and how this impacts on cell survival in the face of environmental stress.

\section{ACKNOWLEDGMENTS}

I.U. is funded by a fellowship from the Fundación Alfonso Martin Escudero.

\section{REFERENCES}

Aldridge BB, Fernandez-Suarez M, Heller D, Ambravaneswaran V, Irimia D, Toner M, Fortune SM. 2012. Asym- metry and aging of mycobacterial cells lead to variable growth and antibiotic susceptibility. Science 335: 100104.

Arora G, Sajid A, Arulanandh MD, Singhal A, Mattoo AR, Pomerantsev AP, Leppla SH, Maiti S, Singh Y. 2012. Unveiling the novel dual specificity protein kinases in Bacillus anthracis: Identification of the first prokaryotic dual specificity tyrosine phosphorylation-regulated kinase (dyrk)-like kinase. J Biol Chem 287: 26749-26763.

Breier AM, Grossman AD. 2007. Whole-genome analysis of the chromosome partitioning and sporulation protein Spo0J (ParB) reveals spreading and origin-distal sites on the Bacillus subtilis chromosome. Mol Microbiol 64: 703-718.

Brieger EM, Glauert AM. 1952. A phase-contrast study of reproduction in mycelial strains of avian tubercle bacilli. J Gen Microbiol 7: 287-294.

Brieger EM, Glauert AM. 1956. Sporelike structures in the tubercle bacillus. Nature 178: 544 .

Brieger EM, Cosslet VE, Glauert AM. 1953. Action of antibiotics on avian tubercle bacilli studied with the electron microscope. Nature 171: 211-212.

Buerger S, Spoering A, Gavrish E, Leslin C, Ling L, Epstein SS. 2012. Microbial scout hypothesis, stochastic exit from dormancy, and the nature of slow growers. Appl Environ Microbiol 78: 3221-3228.

Cangelosi GA, Do JS, Freeman R, Bennett JG, Semret M, Behr MA. 2006. The two-component regulatory system $m \operatorname{tr} A B$ is required for morphotypic multidrug resistance in Mycobacterium avium. Antimicrob Agents Chemother 50: $461-468$.

Carballido-López R. 2006. The bacterial actin-like cytoskeleton. Microbiol Mol Biol Rev 70: 888-909.

Casart Y, Gamero E, Rivera-Gutierrez S, González-Y-Merchand JA, Salazar L. 2008. par genes in Mycobacterium bovis and Mycobacterium smegmatis are arranged in an operon transcribed from "SigGC" promoters. BMC Microbiol 8: 51 .

Champion JA, Mitragotri S. 2006. Role of target geometry in phagocytosis. Proc Natl Acad Sci 103: 4930-4934.

Chaudhuri BN, Dean R. 2011. The evidence of large-scale DNA-induced compaction in the mycobacterial chromosomal ParB. J Mol Biol 413: 901-907.

Cohen-Gonsaud M, Barthe P, Bagnéris C, Henderson B, Ward J, Roumestand C, Keep NH. 2005. The structure of a resuscitation-promoting factor domain from $\mathrm{Myco}$ bacterium tuberculosis shows homology to lysozymes. Nat Struct Mol Biol 12: 270-273.

Dahl JL. 2004. Electron microscopy analysis of Mycobacterium tuberculosis cell division. FEMS Microbiol Lett 240: 15-20.

Daniel RA, Errington J. 2003. Control of cell morphogenesis in bacteria: Two distinct ways to make a rod-shaped cell. Cell 113: 767-776.

Demina GR, Makarov VA, Nikitushkin VD, Ryabova OB, Vostroknutova GN, Salina EG, Shleeva MO, Goncharenko AV, Kaprelyants AS. 2009. Finding of the low molecular weight inhibitors of resuscitation promoting factor enzymatic and resuscitation activity. PLOS ONE 4: e8174. 
Donovan C, Schwaiger A, Krämer R, Bramkamp M. 2010. Subcellular localization and characterization of the ParAB system from Corynebacterium glutamicum. J Bacteriol 192: 3441-3451.

Donovan C, Sieger B, Krämer R, Bramkamp M. 2012. A synthetic Escherichia coli system identifies a conserved origin tethering factor in Actinobacteria. Mol Microbiol 84: 105-116.

Downing KJ, Betts JC, Young DI, McAdam RA, Kelly F, Young M, Mizrahi V. 2004. Global expression profiling of strains harbouring null mutations reveals that the five $r p f$-like genes of Mycobacterium tuberculosis show functional redundancy. Tuberculosis 84: 167-179.

Downing KJ, Mischenko VV, Shleeva MO, Young DI, Young M, Kaprelyants AS, Apt AS, Mizrahi V. 2005. Mutants of Mycobacterium tuberculosis lacking three of the five rpflike genes are defective for growth in vivo and for resuscitation in vitro. Infect Immun 73: 3038-3043.

Ebersbach G, Gerdes K. 2005. Plasmid segregation mechanisms. Annu Rev Genet 39: 453-479.

Farnia P, Mohammad RM, Merza MA, Tabarsi P, Zhavnerko GK, Ibrahim TA, Kuan HO, Ghanavei J, Farnia P, Ranjbar $\mathrm{R}$, et al. 2010. Growth and cell-division in extensive (XDR) and extremely drug resistant (XXDR) tuberculosis strains: Transmission and atomic force observation. Int J Clin Exp Med 3: 308-314.

Fiebig A, Keren K, Theriot JA. 2006. Fine-scale time-lapse analysis of the biphasic, dynamic behaviour of the two Vibrio cholerae chromosomes. Mol Microbiol 60: 11641178.

Gee CL, Papavinasasundaram KG, Blair SR, Baer CE, Falick AM, King DS, Griffin JE, Venghatakrishnan H, Zukauskas A, Wei J-R, et al. 2012. A phosphorylated pseudokinase complex controls cell wall synthesis in mycobacteria. Sci Signal 5: ra7.

Ghosh J, Larsson P, Singh B, Pettersson BMF, Islam NM, Sarkar SN, Dasgupta S, Kirsebom LA. 2009. Sporulation in mycobacteria. Proc Natl Acad Sci 106: 10781-10786.

Gill WP, Harik NS, Whiddon MR, Liao RP, Mittler JE, Sherman DR. 2009. A replication clock for Mycobacterium tuberculosis. Nat Med 15: 211-214.

Ginda K, Bezulska M, Ziółkiewicz M, Dziadek J, Zakrzewska-Czerwińska J, Jakimowicz D. 2013. ParA of Mycobacterium smegmatis co-ordinates chromosome segregation with the cell cycle and interacts with the polar growth determinant DivIVA. Mol Microbiol. 87: 998-1012.

Godin M, Delgado FF, Son S, Grover WH, Bryan AK, Tzur A, Jorgensen P, Payer K, Grossman AD, Kirschner MW, et al. 2010. Using buoyant mass to measure the growth of single cells. Nat Methods 7: 387-390.

Golchin SA, Stratford J, Curry RJ, McFadden J. 2012. A microfluidic system for long-term time-lapse microscopy studies of mycobacteria. Tuberculosis 92: 489-496.

Gopalaswamy R, Narayanan S, Chen B, Jacobs WR, Av-Gay Y. 2009. The serine/threonine protein kinase PknI controls the growth of Mycobacterium tuberculosis upon infection. FEMS Microbiol Lett 295: 23-29.

Gupta RK, Srivastava BS, Srivastava R. 2010. Comparative expression analysis of $r p f$-like genes of Mycobacterium tuberculosis $\mathrm{H} 37 \mathrm{Rv}$ under different physiological stress and growth conditions. Microbiology 156: 2714-2722.
Hatzios SK, Baer CE, Rustad TR, Siegrist MS, Pang JM, Ortega C, Alber T, Grundner C, Sherman DR, Bertozzi CR. 2013. Osmosensory signaling in Mycobacterium tuberculosis mediated by a eukaryotic-like Ser/Thr protein kinase. Proc Natl Acad Sci 110: E5069-E5077.

Hett EC, Rubin EJ. 2008. Bacterial growth and cell division: A mycobacterial perspective. Microbiol Mol Biol Rev 72: 126-156, table of contents.

Hett EC, Chao MC, Steyn AJ, Fortune SM, Deng LL, Rubin EJ. 2007. A partner for the resuscitation-promoting factors of Mycobacterium tuberculosis. Mol Microbiol 66: $658-668$.

Hett EC, Chao MC, Deng LL, Rubin EJ. 2008. A mycobacterial enzyme essential for cell division synergizes with resuscitation-promoting factor. PLoS Pathog 4: e1000001.

Hett EC, Chao MC, Rubin EJ. 2010. Interaction and modulation of two antagonistic cell wall enzymes of mycobacteria. PLoS Pathog 6: e1001020.

Jakimowicz D, Chater K, Zakrzewska-Czerwínska J. 2002. The ParB protein of Streptomyces coelicolor A3(2) recognizes a cluster of parS sequences within the origin-proximal region of the linear chromosome. Mol Microbiol 45: 1365-1377.

Jakimowicz D, Brzostek A, Rumijowska-Galewicz A, Zydek P, Dołzbłasz A, Smulczyk-Krawczyszyn A, Zimniak T, Wojtasz L, Zawilak-Pawlik A, Kois A, et al. 2007. Characterization of the mycobacterial chromosome segregation protein ParB and identification of its target in Mycobacterium smegmatis. Microbiology 153: 4050-4060.

Jo E-K. 2008. Mycobacterial interaction with innate receptors: TLRs, C-type lectins, and NLRs. Curr Opin Infect Dis 21: 279-286.

Joyce G, Robertson BD, Williams KJ. 2011. A modified agar pad method for mycobacterial live-cell imaging. BMC Res Notes 4: 73.

Joyce G, Williams KJ, Robb M, Noens E, Tizzano B, Shahrezaei V, Robertson BD. 2012. Cell division site placement and asymmetric growth in mycobacteria. PLoS ONE 7: e44582.

Kana BD, Mizrahi V. 2010. Resuscitation-promoting factors as lytic enzymes for bacterial growth and signaling. FEMS Immunol Med Microbiol 58: 39-50.

Kana BD, Gordhan BG, Downing KJ, Sung N, Vostroktunova G, Machowski EE, Tsenova L, Young M, Kaprelyants A, Kaplan G, et al. 2008. The resuscitation-promoting factors of Mycobacterium tuberculosis are required for virulence and resuscitation from dormancy but are collectively dispensable for growth in vitro. Mol Microbiol 67: $672-684$.

Kana BD, Mizrahi V, Gordhan BG. 2010. Depletion of resuscitation-promoting factors has limited impact on the drug susceptibility of Mycobacterium tuberculosis. J Antimicrob Chemother 65: 1583-1585.

Kang C-M, Nyayapathy S, Lee J-Y, Suh J-W, Husson RN. 2008. Wag31, a homologue of the cell division protein DivIVA, regulates growth, morphology and polar cell wall synthesis in mycobacteria. Microbiology 154: 725-735.

Kondratieva T, Rubakova E, Kana BD, Biketov S, Potapov V, Kaprelyants A, Apt A. 2011. Mycobacterium tuberculosis attenuated by multiple deletions of rpf genes effectively protects mice against TB infection. Tuberculosis 91: 219223. 
I. Uhía et al.

Kruse K, Howard M, Margolin W. 2007. An experimentalist's guide to computational modelling of the Min system. Mol Microbiol 63: 1279-1284.

Kumar D, Narayanan S. 2012. pknE, a serine/threonine kinase of Mycobacterium tuberculosis modulates multiple apoptotic paradigms. Infect Genet Evol 12: 737-747.

Kumar D, Palaniyandi K, Challu VK, Kumar P, Narayanan S. 2013. PknE, a serine/threonine protein kinase from $M y$ cobacterium tuberculosis has a role in adaptive responses. Arch Microbiol 195: 75-80.

Kussell E, Leibler S. 2005. Phenotypic diversity, population growth, and information in fluctuating environments. Science 309: 2075-2078.

Kysela DT, Brown PJB, Huang KC, Brun YV. 2013. Biological consequences and advantages of asymmetric bacterial growth. Аnпu Rev Microbiol 67: 417-435.

Lakshminarayan H, Narayanan S, Bach H, Sundaram KGP, Av-Gay Y. 2008. Molecular cloning and biochemical characterization of a serine threonine protein kinase, $\mathrm{PknL}$, from Mycobacterium tuberculosis. Protein Expr Purif 58: 309-317.

Lamont EA, Bannantine JP, Armién A, Ariyakumar DS, Sreevatsan S. 2012. Identification and characterization of a spore-like morphotype in chronically starved $\mathrm{Myco-}$ bacterium avium subsp. paratuberculosis cultures. PLoS ONE 7: e30648.

Lee PJ, Gaige TA, Hung PJ. 2009. Dynamic cell culture: A microfluidic function generator for live cell microscopy. Lab Chip 9: 164-166.

Letek M, Fiuza M, Ordóñez E, Villadangos AF, Ramos A, Mateos LM, Gil JA. 2008. Cell growth and cell division in the rod-shaped actinomycete Corynebacterium glutamicum. Antonie Van Leeuwenhoek 94: 99-109.

Lin DC, Grossman AD. 1998. Identification and characterization of a bacterial chromosome partitioning site. Cell 92: 675-685.

Locke JCW, Elowitz MB. 2009. Using movies to analyse gene circuit dynamics in single cells. Nat Rev Microbiol 7: 383392.

Makinoshima H, Glickman MS. 2005. Regulation of Mycobacterium tuberculosis cell envelope composition and virulence by intramembrane proteolysis. Nature 436: 406409.

Malhotra V, Arteaga-Cortés LT, Clay G, Clark-Curtiss JE. 2010. Mycobacterium tuberculosis protein kinase $\mathrm{K}$ confers survival advantage during early infection in mice and regulates growth in culture and during persistent infection: Implications for immune modulation. Microbiology 156: $2829-2841$.

Maloney E, Madiraju M, Rajagopalan M. 2009. Overproduction and localization of Mycobacterium tuberculosis ParA and ParB proteins. Tuberculosis 89: S65-S69.

Mir M, Wang Z, Shen Z, Bednarz M, Bashir R, Golding I, Prasanth SG, Popescu G. 2011. Optical measurement of cycle-dependent cell growth. Proc Natl Acad Sci 108: 13124-13129.

Moker N, Brocker M, Schaffer S, Kramer R, Morbach S, Bott M. 2004. Deletion of the genes encoding the MtrA-MtrB two-component system of Corynebacterium glutamicum has a strong influence on cell morphology, antibiotics susceptibility and expression of genes involved in osmoprotection. Mol Microbiol 54: 420-438.

Molle V, Kremer L. 2010. Division and cell envelope regulation by Ser/Thr phosphorylation: Mycobacterium shows the way. Mol Microbiol 75: 1064-1077.

Mukamolova GV, Turapov OA, Kazarian K, Telkov M, Kaprelyants AS, Kell DB, Young M. 2002. The rpf gene of Micrococcus luteus encodes an essential secreted growth factor. Mol Microbiol 46: 611-621.

Mukamolova GV, Murzin AG, Salina EG, Demina GR, Kell DB, Kaprelyants AS, Young M. 2006. Muralytic activity of Micrococcus luteus Rpf and its relationship to physiological activity in promoting bacterial growth and resuscitation. Mol Microbiol 59: 84-98.

Murray H, Ferreira H, Errington J. 2006. The bacterial chromosome segregation protein Spo0J spreads along DNA from parS nucleation sites. Mol Microbiol 61: 1352-1361.

Nguyen HT, Wolff KA, Cartabuke RH, Ogwang S, Nguyen L. 2010. A lipoprotein modulates activity of the MtrAB twocomponent system to provide intrinsic multidrug resistance, cytokinetic control and cell wall homeostasis in Mycobacterium. Mol Microbiol 76: 348-364.

Nikitushkin VD, Demina GR, Shleeva MO, Kaprelyants AS. 2013. Peptidoglycan fragments stimulate resuscitation of "non-culturable" mycobacteria. Antonie Van Leeuwenhoek 103: 37-46.

Nisa S, Blokpoel MCJ, Robertson BD, Tyndall JDA, Lun S, Bishai WR, O’Toole R. 2010. Targeting the chromosome partitioning protein ParA in tuberculosis drug discovery. J Antimicrob Chemother 65: 2347-2358.

Plocinska R, Purushotham G, Sarva K, Vadrevu IS, Pandeeti EVP, Arora N, Plocinski P, Madiraju MV, Rajagopalan M 2012. Septal localization of the Mycobacterium tuberculosis MtrB sensor kinase promotes MtrA regulon expression. J Biol Chem 287: 23887-23899.

Ptacin JL, Shapiro L. 2010. Initiating bacterial mitosis: Understanding the mechanism of ParA-mediated chromosome segregation. Cell Cycle 9: 4033-4034.

Raman S, Hazra R, Dascher CC, Husson RN. 2004. Transcription regulation by the Mycobacterium tuberculosis alternative sigma factor $\mathrm{SigD}$ and its role in virulence. J Bacteriol 186: 6605-6616.

Rickman L, Scott C, Hunt DM, Hutchinson T, Menéndez MC, Whalan R, Hinds J, Colston MJ, Green J, Buxton RS. 2005. A member of the cAMP receptor protein family of transcription regulators in Mycobacterium tuberculosis is required for virulence in mice and controls transcription of the $r p f A$ gene coding for a resuscitation promoting factor. Mol Microbiol 56: 1274-1286.

Ringgaard S, van Zon J, Howard M, Gerdes K. 2009. Movement and equipositioning of plasmids by ParA filament disassembly. Proc Natl Acad Sci 106: 19369-19374.

Romano M, Aryan E, Korf H, Bruffaerts N, Franken CLMC, Ottenhoff THM, Huygen K. 2012. Potential of Mycobacterium tuberculosis resuscitation-promoting factors as antigens in novel tuberculosis sub-unit vaccines. Microbes Infect 14: 86-95.

Sajid A, Arora G, Gupta M, Upadhyay S, Nandicoori VK, Singh Y. 2011. Phosphorylation of Mycobacterium tuberculosis Ser/Thr phosphatase by PknA and PknB. PLoS ONE 6: e17871. 
Santi I, Dhar N, Bousbaine D, Wakamoto Y, McKinney JD 2013. Single-cell dynamics of the chromosome replication and cell division cycles in mycobacteria. Nat Commun 4: 2470 .

Sassetti CM, Boyd DH, Rubin EJ. 2003. Genes required for mycobacterial growth defined by high density mutagenesis. Mol Microbiol 48: 77-84.

Singh B, Ghosh J, Islam NM, Dasgupta S, Kirsebom LA. 2010. Growth, cell division and sporulation in mycobacteria. Antonie Van Leeuwenhoek 98: 165-177.

Singh B, Nitharwal RG, Ramesh M, Pettersson BMF, Kirsebom LA, Dasgupta S. 2013. Asymmetric growth and division in Mycobacterium spp.: Compensatory mechanisms for non-medial septa. Mol Microbiol 88: 64-76.

Squeglia F, Romano M, Ruggiero A, Vitagliano L, De Simone A, Berisio R. 2013. Carbohydrate recognition by RpfB from Mycobacterium tuberculosis unveiled by crystallographic and molecular dynamics analyses. Biophys J 104: 2530-2539.

Stastná J, Goodfellow M, Kristůfek V, Novotná J, Jizba J, Cáslavská J, Kofronová O, Blumauerová M. 1992. Characteristics of Streptomyces globisporus strain 0234A forming endospores in submerged cultures. Folia Microbiol (Praha) 37: 111-116.

Telkov MV, Demina GR, Voloshin SA, Salina EG, Dudik TV, Stekhanova TN, Mukamolova GV, Kazaryan KA, Goncharenko AV, Young M, et al. 2006. Proteins of the Rpf (resuscitation promoting factor) family are peptidoglycan hydrolases. Biochemistry (Mosc) 71: 414-422.

Thanbichler M, Shapiro L. 2006. MipZ, a spatial regulator coordinating chromosome segregation with cell division in Caulobacter. Cell 126: 147-162.

Thanky NR, Young DB, Robertson BD. 2007. Unusual features of the cell cycle in mycobacteria: Polar-restricted growth and the snapping-model of cell division. Tuberculosis 87: 231-236.
Mycobacterial Growth

Tostevin F, Wolde ten PR, Howard M. 2007. Fundamental limits to position determination by concentration gradients. PLoS Comp Biol 3: e78.

Traag BA, Driks A, Stragier P, Bitter W, Broussard G, Hatfull G, Chu F, Adams KN, Ramakrishnan L, Losick R. 2010 Do mycobacteria produce endospores? Proc Natl Acad Sci 107: $878-881$.

Tufariello JM, Jacobs WR, Chan J. 2004. Individual Mycobacterium tuberculosis resuscitation-promoting factor homologues are dispensable for growth in vitro and in vivo. Infect Immun 72: 515-526.

Velayati AA, Farnia P, Ibrahim TA, Haroun RZ, Kuan HO, Ghanavi J, Farnia P, Kabarei AN, Tabarsi P, Omar AR, et al. 2009a. Differences in cell wall thickness between resistant and nonresistant strains of Mycobacterium tuberculosis: Using transmission electron microscopy. Chemotherapy 55: 303-307.

Velayati AA, Farnia P, Masjedi MR, Ibrahim TA, Tabarsi P, Haroun RZ, Kuan HO, Ghanavi J, Varahram M. 2009b. Totally drug-resistant tuberculosis strains: Evidence of adaptation at the cellular level. Eur Respir J 34: 12021203.

Wakamoto Y, Dhar N, Chait R, Schneider K, Signorino-Gelo F, Leibler S, McKinney JD. 2013. Dynamic persistence of antibiotic-stressed mycobacteria. Science 339: 91-95.

Warner DF, Mizrahi V. 2012. A pseudokinase debut at the mycobacterial cell wall. Sci Signal 5: pe3.

Wivagg CN, Hung DT. 2012. Resuscitation-promoting factors are required for $\beta$-lactam tolerance and the permeability barrier in Mycobacterium tuberculosis. Antimicrob Agents Chemother 56: 1591-1594.

Zhang YJ, Ioerger TR, Huttenhower C, Long JE, Sassetti CM, Sacchettini JC, Rubin EJ. 2012. Global assessment of genomic regions required for growth in Mycobacterium tuberculosis. PLoS Pathog 8: e1002946. 


\section{$\&_{\mathrm{CSH}}^{\infty} \&$ Cold Spring Harbor

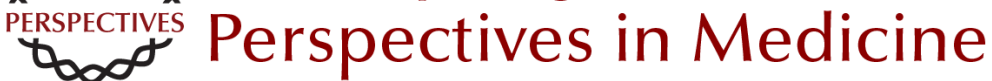

\section{Mycobacterial Growth}

Iria Uhía, Kerstin J. Williams, Vahid Shahrezaei and Brian D. Robertson

Cold Spring Harb Perspect Med 2015; doi: 10.1101/cshperspect.a021097 originally published online May 8,2015

\section{Subject Collection Tuberculosis}

Transmission and Institutional Infection Control of Tuberculosis Edward A. Nardell

Innate and Adaptive Cellular Immune Responses

to Mycobacterium tuberculosis Infection Katrin D. Mayer-Barber and Daniel L. Barber

Tuberculosis Comorbidity with Communicable and Noncommunicable Diseases Matthew Bates, Ben J. Marais and Alimuddin Zumla

Host-Directed Therapies for Tuberculosis David M. Tobin

Immunity and Immunopathology in the Tuberculous Granuloma Antonio J. Pagán and Lalita Ramakrishnan

Tuberculosis Drug Development: History and Evolution of the Mechanism-Based Paradigm? Sumit Chakraborty and Kyu Y. Rhee

Genetic Approaches to Facilitate Antibacterial Drug Development Dirk Schnappinger

The Tuberculosis Drug Discovery and Development Pipeline and Emerging Drug Targets Khisimuzi Mdluli, Takushi Kaneko and Anna Upton
Clinical Aspects of Adult Tuberculosis Robert Loddenkemper, Marc Lipman and Alimuddin Zumla

Advances in Diagnostic Assays for Tuberculosis Stephen D. Lawn

\section{Diagnosis and Management of Latent}

Tuberculosis Infection

Laura Muñoz, Helen R. Stagg and Ibrahim Abubakar

Mycobacterial Growth Iria Uhía, Kerstin J. Williams, Vahid Shahrezaei, et al.

Multidrug-Resistant Tuberculosis and Extensively

Drug-Resistant Tuberculosis Kwonjune J. Seung, Salmaan Keshavjee and Michael L. Rich

The Mycobacterial Cell Wall--Peptidoglycan and

Arabinogalactan Luke J. Alderwick, James Harrison, Georgina S. Lloyd, et al.

Tuberculosis and HIV Coinfection Judith Bruchfeld, Margarida Correia-Neves and Gunilla Källenius

Imaging in Tuberculosis Jamshed B. Bomanji, Narainder Gupta, Parveen Gulati, et al.

For additional articles in this collection, see http://perspectivesinmedicine.cshlp.org/cgi/collection/ 